\title{
A Study on the Perceived Gap in Between Industry and Academia with Reference to the Curriculum of Post-Graduate Courses In Pharmaceutical Sciences in india
}

\author{
Gouri Palsokar, Madhukar Tajne \\ Department of Pharmaceutical Sciences, RTM Nagpur University, Nagpur Maharashtra.INDIA
}

\begin{abstract}
The rapid growth of pharmaceutical industry in India has resulted into an increased demand for skilled and trained graduates and post-graduates in pharmaceutical sciences over the last decade. Over a period of time due to the rapid development and changing technology, academic institutions have not been able to produce pharmacists who are productive and readily employable. Thus, resulting in a gap between industry and academia. Aim: The present study aims to identify the gap which exists in industry and academia by taking views of select professionals from the pharmaceutical industry and faculty from academic institutions. Attempts have also been made to explore various measures suggested by respondents to bridge the gap between industry and academia. Methods: A questionnaire was administered to the faculty of academic institutions and professionals working in different areas of the pharmaceutical industry across India by meeting them personally. 320 faculty from 38 academic institutions and 312 professionals from 30 industries were selected for the study. Results: Results were quantified on the basis of their M. Pharm specialisations or their area of work in the industry. $90 \%$ of faculty and $94 \%$ of professionals from industry responded to the survey. Data was analysed statistically by applying Proportionality test. More than $80 \%$ of academicians and people from industry opined that there exists a gap in industry and academia whereas, they had differences of opinion about additional courses to be taken by students so as to make them industry ready and readily employable. Conclusion: Revamping of post graduate education in pharmaceutical sciences by focusing on industry -academia collaboration, building fundamental concepts, emphasizing practical exposure to latest technologies and techniques used in industry, encouraging faculty and students for industrial training can help bridge the gap in industry and academia.
\end{abstract}

Key words: Pharmaceutical Education, Post Graduate Courses, Industry- Academia Linkage, Pharmaceutical Sciences, Proportionality test.

Key Messages: In spite of the increase in the number of institutions offering postgraduates courses, availability of readily employable manpower remains a concern for the pharmaceutical industry. This research establishes that educational reforms in terms of making a robust curriculum design with active participation of the industry is the need of the day.

Submission Date: 21-04-2017; Revision Date: 13-07-2017; Accepted Date: 10-01-2018

DOI: 10.5530/ijper.52.1.2 Correspondence: Gouri Palsokar, Department of Pharmaceutical Sciences, RTM Nagpur University, Nagpur Maharashtra. INDIA Phone no: 9096051456 Email ID: gouripalsokar@ gmail.com

\section{INTRODUCTION}

India is a hub of Pharmaceutical industries in the world. The Indian pharmaceutical sector is today considered as a source of good quality low cost generic drugs. Globally this industry is ranked third in terms of

volume and fourteenth in terms of value. ${ }^{1}$ According to the Department of Pharmaceuticals, Government of India, the export of medicinal and pharmaceutical products had reached over 6.9 lakh crore rupees

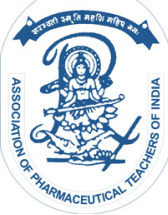

www.ijper.org 
during the financial year 2013-2014 and is expected to reach 10 lakh crores by 2016-2017. The total income of the drug and pharmaceutical industry in India during 2015-2016 was estimated to be 1.853 lakh crore rupees. ${ }^{2}$ This growth has resulted in increasing the demand for trained manpower in the pharmaceutical sector, thus increasing the demand of trained graduates and postgraduates in pharmaceutical Sciences. ${ }^{3}$ The Pharmaceutical industry being the largest recruiter of these graduates and post-graduates employs students in areas like Formulation \& Development, Analytical development, Production, Quality Control and Quality Assurance, Intellectual Property Rights, Regulatory Affairs, Marketing \& Sales, Clinical Research. ${ }^{4,5}$ As a result, the curriculum of graduate and post-graduate courses in pharmaceutical sciences in India is industry oriented and not practice oriented. ${ }^{6}$ Due to the rapid industrialisation in the Pharmaceutical sector and the demand for professionals, there has been a rapid growth in the number of institutions imparting education in pharmaceutical sciences at the graduate and post-graduate level in recent years. The growth of pharmaceutical industry, of course, depends on the employment of able and competent pharmacists and this seems to be one of the major reason for proliferation of pharmacy colleges in India. ${ }^{7}$ Pharmaceutical education in India is imparted through diverse set-ups and varied backgrounds at various State \& Central Universities, Aided \& Unaided private affiliated institutions, Institutions of National Importance like Indian Institutes of Technology (IIT) \& National Institute of Pharmaceutical Education \& Research (NIPER), Deemed Universities and more recently Private State Universities. According to the data released by the All India Council for Technical Education (AICTE) for the year 2016-2017, there are about 1523 institutions with a collective intake of around 169686 seats offering courses in Pharmaceutical sciences. ${ }^{8}$ Out of these institutions, 1335 are private unaided institutions which are affiliated to Universities and follow the curriculum designed by the respective Universities. In India almost, all under graduate and post graduate courses in Pharmaceutical sciences are designed to meet the needs of the pharmaceutical industry, unlike countries like USA, UK and European nations where the pharmaceutical education is oriented towards pharmacy practise., ${ }^{9,10}$ The curriculum taught at the under graduate level in Pharmaceutical sciences exposes a student to all the relevant areas and equips him/her to pursue a specialisation at the post graduate level. During these degree courses a student is expected to develop analytical skills, problem solving approach and research aptitude so as to make him industry-ready. ${ }^{11}$ However, over a period of time, academics has not been able to keep up to the pace of the fast changing scenario in the industry, resulting into a gap in between the requirements \& expectations of the Industry and the skills acquired by a student during their course. ${ }^{12,13}$ This difference between what is taught and the actual requirement of the industry is a major concern for the Industry as they have to invest in the training of such incumbents. ${ }^{14}$ Moreover, in the present situation where India is ushering into a new era of reforms, it becomes extremely important to identify key areas of reforms in the education sector in order to meet the expectations of the Industry. ${ }^{15,16}$

This research aims to identify the potential gaps perceived by the Pharmaceutical industry and academicians with respect to the curriculum of the post-graduate degree courses in pharmaceutical sciences. It can thus provide a handy reference to the academia to tune the curriculum as per Industry standards and make students employable.

\section{OBJECTIVE}

The objective of the proposed research is to examine whether post-graduate courses in pharmaceutical sciences in India provide education to an adequate extent and whether they cater to the exact needs of the Industry. In order to do so it is necessary to examine, whether there is any gap existing in industry and academia by analysing the views of people employed in the Industry and academia with varied experience. In case of any gap, identify those gaps and explores avenues as suggested by the respondents to ensure a dynamic education system to be able to equip students with technical knowledge and skills to fulfil the needs of the pharmaceutical industry and the ever-changing health care sector.

\section{MATERIALS AND METHODS}

A detailed questionnaire was prepared to collect the responses of two important stakeholders of Pharmaceutical education viz. Faculty and Industry professionals. All the respondents selected were post-graduates in pharmaceutical sciences. A pilot study was performed using a sample size of 10 for both category of respondents. The suggestions thus received were incorporated and a final questionnaire was prepared for each category after due validation. The questionnaire designed for each category of respondents had two sections. The first section was designed to collect demographic information of the respondent and the second section had questions related to the curriculum in post-graduate courses in Pharmaceutical Sciences and employability of students. To maximise the response rate, the questionnaire was 
kept relatively short. Out of the two questions asked in Section II, first was a closed ended question while the second question was open ended for taking suggestions to improve the employability quotient of a student.

Between July 2015 and June 2016 questionnaires were manually distributed in thirty-eight academic institutions and thirty Pharmaceutical industries across India. Various academic institutions like NIPER's, University Departments, Autonomous Institutions, Affiliated Aided and Un-Aided Institutions across India were selected for conducting the survey. The author personally visited these institutions and administered the data collection process by distributing the questionnaires to faculty. This process was carried out by taking prior approvals from the head of the institution. Individual interactions were done with Faculty respondents to explain them the objective of the study and questionnaires were distributed to them. Faculty respondents were given a days' time to fill the questionnaire. Those who could not fill the questionnaire on the same day, were provided with the link for the electronic questionnaire to be filled at their convenience. Respondents whose responses were not received within seven days, were reminded via a reminder e-mail.

Responses from Industry professionals were taken by taking advance appointments with the concerned officials through the Human Recourses and Administration departments of the respective industries. Professionals working in thirty industries at different positions, with varied experiences and specialisations were selected for the study. The industries visited included Multinational companies, companies of Indian origin as well as Small and Medium scale enterprises. The author personally visited all the industries and collected the responses of the industry professionals by interacting with them and through a paper based self-administered questionnaire. Electronic questionnaires were sent to certain professionals who could not spare time to fill the questionnaire on the same day. The response rates are summarised in Table 1.

All the responses received were coded and tabulated using MS-Excel a spread-sheet package. In order to understand the exact views of faculty and industry professionals the respondents from both the categories were divided into four groups based on their experience i.e. Less than 2 years, 2-5 years, 5-10 years and more than 10 years of experience. The population was further divided on the basis of their specialisation at post-graduate level or their current area of work. The data was cleansed and was analysed using the statistical package 'R'. Descriptive statistics and proportionality test was used to analyse and interpret data. Personal interviews were also conducted for very senior people in the Industry and academics and their views were noted.

\section{RESULTS}

The primary objective of this research was to identify whether the faculty and professionals from the industry believe that there is a gap in the curriculum taught at post-graduate level in pharmaceutical sciences and the requirements of the Industry. The overall percentage of respondents who were of the view that there exists a gap is tabulated in Table. 2. Proportionality test was applied to find whether there is a difference in the opinion amongst the respective groups. The $\mathrm{p}$ value was found to be 0.634 which indicates that the opinion of both the groups is similar and they are of the view that there exists a gap in the curriculum being taught and the requirements of the Industry.

Further, it was required to investigate whether additional courses were required to be taught to bridge the gap. The overall responses of both the groups with respect to their views about additional courses to be taught are tabulated in Table 3. The results of proportionality test on the responses indicate a significant difference of opinions of Academicians and Industry professionals as indicated by the $\mathrm{p}$ value of 0.00000375 .

It is pertinent to note that, in-spite of $80 \%$ of the respondents from both the groups having an opinion that there exists a gap between academics and Industry needs, their views regarding requirement of additional courses to be taught to students at PG level differ significantly. Hence, further drilling down was required.

For further investigation respondents from Industry and Academia were divided into four groups based on their experience and the responses were segregated. The views along with the results of proportionality test are as shown in Table 4.

No significant variation is observed in the views of respondents having less than two years of experience. The percentage response of professionals having more than two years of experience are greater than those having less than two years of experience. Moreover, there is a significant variation observed amongst the two respondent groups with more than two years of experience. A large population of Industry professionals having more than ten years of experience are of the view that there exists a gap in industry and academia.

Similarly, the responses of Industry professionals and faculty with reference to the requirement of additional courses, grouped on the basis of their experience is as shown in Table 5. 


\section{Table 1: Response rate for the questionnaire}

\begin{tabular}{|c|c|c|c|}
\hline Type of Respondents & $\begin{array}{c}\text { Respondents considered } \\
\text { for the Study }\end{array}$ & $\begin{array}{c}\text { Number of respondents } \\
\text { who responded }\end{array}$ & $\begin{array}{c}\text { Response } \\
\text { rate }\end{array}$ \\
\hline Faculty & 320 & 291 & $90.93 \%$ \\
\hline Industry Professionals & 312 & 296 & $94.87 \%$ \\
\hline
\end{tabular}

\begin{tabular}{|c|c|c|c|}
\hline \multicolumn{4}{|c|}{ Table 2: Percentage of respondents indicating gap in curriculum } \\
\hline Industry Professionals & Faculty & P Value & Result \\
\hline $82 \%$ & $83 \%$ & 0.634 & No Significant Difference \\
\hline
\end{tabular}

Table 3: Percentage of respondents indicating the need for additional courses.

\begin{tabular}{|c|c|c|c|}
\hline Industry Professionals & Faculty & P Value & Result \\
\hline $56 \%$ & $43 \%$ & 0.00000375 & Significant Difference is observed \\
\hline
\end{tabular}

\begin{tabular}{|c|c|c|c|c|}
\hline \multicolumn{4}{|c|}{$\begin{array}{c}\text { Table 4: Percentage response of Industry professionals and faculty regarding gap } \\
\text { in industry and academics grouped by their work experience }\end{array}$} \\
\hline Experience in Years & $\begin{array}{c}\text { Industry } \\
\text { Professionals }\end{array}$ & Faculty & P Value & Results \\
\hline Less than 2 & $72 \%$ & $74 \%$ & 0.438 & No Significant variation \\
\hline 2 to 5 & $85 \%$ & $94 \%$ & 0.000087 & Significant Variation \\
\hline 5 to 10 & $89 \%$ & $84 \%$ & 0.000179 & Significant Variation \\
\hline More than 10 & $90 \%$ & $84 \%$ & 0.000234 & Significant Variation \\
\hline
\end{tabular}

\begin{tabular}{|c|c|c|c|c|}
\hline \multicolumn{3}{|c|}{ Table 5: Percentage response of Industry Professionals and faculty regarding the } \\
requirement of Additional Courses.
\end{tabular}

From Table 5 it is observed that a large percentage of faculty and professionals form the industry with an experience of five to ten years are of the view that additional courses are required to be taught. It is thus evident that professionals with a significant level of experience in industry and academics were largely of the view that industry specific courses should be done by students over and above their regular PG degrees.

To further drill down and to analyse the views of respondents, they were further segregated on the basis of their M. Pharm specialisation for faculty and their area of expertise for industry professionals. Views of respondents were subjected to proportionality test.
The responses of faculty and industry professionals having Chemistry as their M. Pharm specialisation or working in the area of synthetic chemistry and analytic development, with respect to the gap and requirement of additional courses are presented in Table 6 and Table 7 respectively.

The percentage responses of faculty and industry professionals with respect to the gap and the need for additional courses having Pharmaceutics, Quality Assurance, Pharmacology and Pharmacognosy as their M. Pharm specialisation or working in the respective area along with the results of Proportionality test are tabulated in Table $8 \& 9$, Table $10 \& 11$, Table $12 \& 13$ and Table $14 \& 15$ respectively. 


\begin{tabular}{|c|c|c|c|c|}
\multicolumn{5}{|c|}{ Table 6: Percentage responses of respondents having Chemistry specialisation } \\
Experience in Years & $\begin{array}{c}\text { Industry } \\
\text { Professionals }\end{array}$ & Faculty & P Value & Results \\
\hline Less than 2 & $80 \%$ & $72 \%$ & 0.000749 & Significant variation \\
\hline 2 to 5 & $82 \%$ & $100 \%$ & 0.472 & No Significant Variation \\
\hline 5 to 10 & $92 \%$ & $87 \%$ & 0.000217 & Significant Variation \\
\hline More than 10 & $96 \%$ & $80 \%$ & 0.0000361 & Significant Variation \\
\hline
\end{tabular}

\begin{tabular}{|c|c|c|c|c|}
\hline \multicolumn{5}{|c|}{$\begin{array}{c}\text { Table 7: Percentage responses of respondents having Chemistry specialisation } \\
\text { regarding the need for additional courses. }\end{array}$} \\
\hline Experience in Years & $\begin{array}{c}\text { Industry } \\
\text { Professionals }\end{array}$ & Faculty & P Value & Results \\
\hline Less than 2 & $59 \%$ & $59 \%$ & 0.89 & No Significant variation \\
\hline 2 to 5 & $47 \%$ & $60 \%$ & 0.0000036 & Significant Variation \\
\hline 5 to 10 & $77 \%$ & $61 \%$ & 0.00082 & Significant Variation \\
\hline More than 10 & $54 \%$ & $55 \%$ & 0.79 & No Significant Variation \\
\hline
\end{tabular}

\begin{tabular}{|c|c|c|c|c|}
\hline \multicolumn{5}{|c|}{ Table 8: Percentage responses of respondents having Pharmaceutics specialisation } \\
regarding gap in industry and academia
\end{tabular}

\begin{tabular}{|c|c|c|c|c|}
\multicolumn{5}{|c|}{ Table 9: Percentage responses of respondents having Pharmaceutics specialisation regarding the need } \\
for additional courses
\end{tabular}

Table 10: Percentage responses of respondents having Quality Assurance specialisation regarding gap
in industry and academia.


Table 11: Percentage responses of respondents having Quality Assurance specialisation regarding the need for additional courses

\begin{tabular}{|c|c|c|c|c|}
\hline Experience in Years & $\begin{array}{c}\text { Industry } \\
\text { Professionals }\end{array}$ & Faculty & P Value & Results \\
\hline Less than 2 & $54 \%$ & $63 \%$ & 0.0000032 & Significant variation \\
\hline 2 to 5 & $54 \%$ & $0 \%$ & 0 & No Significant Variation \\
\hline 5 to 10 & $83 \%$ & $62 \%$ & 0.00038 & Significant Variation \\
\hline More than 10 & $59 \%$ & $43 \%$ & 0.000067 & Significant Variation \\
\hline
\end{tabular}

\begin{tabular}{|c|c|c|c|c|}
\hline \multicolumn{4}{|c|}{ Table 12 : Percentage responses of respondents having Pharmacology specialisation regarding gap in } \\
industry and academia & Results \\
\hline Experience in Years & $\begin{array}{c}\text { Industry } \\
\text { Professionals }\end{array}$ & Faculty & P Value & No Significant variation \\
\hline Less than 2 & $70 \%$ & $67 \%$ & 0.31 & No Significant Variation \\
\hline 2 to 5 & $78 \%$ & $67 \%$ & 0.47 & Significant Variation \\
\hline 5 to 10 & $88 \%$ & $60 \%$ & 0.000083 & Significant Variation \\
\hline More than 10 & $93 \%$ & $80 \%$ & 0.0000067 & \\
\hline
\end{tabular}

\begin{tabular}{|c|c|c|c|c|}
\multicolumn{5}{|c|}{ Table 13: Percentage responses of respondents having Pharmacology specialisation regarding the need } \\
for additional courses \\
Experience in Years & $\begin{array}{c}\text { Industry } \\
\text { Professionals }\end{array}$ & Faculty & P Value & Results \\
\hline Less than 2 & $40 \%$ & $48 \%$ & 0.49 & No Significant variation \\
\hline 2 to 5 & $44 \%$ & $33 \%$ & 0.0000029 & Significant Variation \\
\hline 5 to 10 & $75 \%$ & $50 \%$ & 0.0000082 & Significant Variation \\
\hline More than 10 & $64 \%$ & $20 \%$ & 0.0000045 & Significant Variation \\
\hline
\end{tabular}

\begin{tabular}{|c|c|c|c|c|}
\hline \multicolumn{4}{|c|}{ Table 14 : Percentage responses of respondents having Pharmacognosy specialisation regarding gap in } \\
industry and academia & Results \\
\hline Experience in Years & $\begin{array}{c}\text { Industry } \\
\text { Professionals }\end{array}$ & Faculty & P Value & Significant variation \\
\hline Less than 2 & $80 \%$ & $70 \%$ & 0.00042 & No Significant Variation \\
\hline 2 to 5 & $83 \%$ & $100 \%$ & 0.38 & Significant Variation \\
\hline 5 to 10 & $88 \%$ & $92 \%$ & 0.00072 & No Significant Variation \\
\hline More than 10 & $93 \%$ & $90 \%$ & 0.27 & \\
\hline
\end{tabular}

Table 15 : Percentage responses of respondents having Pharmacognosy specialisation regarding the
need for additional courses




\section{DISCUSSION}

This study has revealed many interesting findings about whether there exists a gap in academics and what is required by the industry, whether additional skills are necessary to be acquired by taking up additional courses or whether the curriculum needs to be updated with some recent courses as per the needs of the industry. From Table 2 it is observed that more than $80 \%$ professionals from industry and academics opined that there exists a gap in the curriculum of Post-graduate courses in pharmaceutical sciences and the Industry expectations from these post graduate students. But on the other hand, when they were asked whether there is a need of additional courses to be taught to make the students industry ready, 56\% respondents from the industry were for it, whereas only $43 \%$ faculty shared this opinion. This drop-in percentage responses amongst both groups of respondents for the two questions might be because the respondents were not exactly sure about the additional inputs to be given to students in form of courses to make them readily employable.

Further, when the respondent groups were divided into four, based on their experience, it was observed that respondents with more than two years of experience were of the majority view that there exists a gap between industry and academics as compared to respondents with less than two years of experience.

The respondent group of 0-2 and 2-5 years of experience were not clear with the requirement of additional courses as they are merely responsible for executing projects or jobs delegated to them by senior professionals, which is true in case of responses received even from faculty in educational institutions. Since this group of respondents have recently completed their post-graduation and are relatively new to the trade, they are the ones whose percentage responses to the first question relating to the gap between industry and academics are the maximum. But since they lack experience they were unable to pin point the gap in clear terms which is evident from the analysis represented in Table 4 and 5.

Similarly, respondents from industry and academics with 5-10 years of experience were of the majority opinion that additional courses were required to be taught or undertaken by students to make them industry ready. This indicates that they have a clear idea as to what the industry requires. These respondents could also correlate the gap and had proposed many courses which could be taught to the PG students to increase their employability factor. And hence, opinion of this group of respondents is of prime importance here.
The percentage of respondents with more than ten years of experience is seen to be high in pointing out the gap but could not propose viable solutions as most of them were at managerial positions in the industry and have lost touch with academics and the hard-core work which is mostly executed by mid-level managers with 5-10 years of experience.

It is also observed that the justification of requirement of additional inputs to be given to students is more precisely given by industry professionals and by faculty having an active industry-connect. The major reason for the industry professionals pressing for additional courses, is the demand for skilled and industry ready manpower so as to reduce the training costs of new recruits. During the personal interactions with faculty members many senior faculty opined that the M. Pharm curriculum gives a student a strong base in the respective specialisation and helps in getting a better understanding of the subject. This grounding helps the students to understand industry processes and helps them develop their skills over a period of time. Most of the faculty were of the view that academic institutions imparting post graduate education in Pharmaceutical Sciences should not act as centres for vocational training.

To further investigate the responses in a systematic manner, the respondents were grouped on the basis of their specialisation at post-graduate level viz. Pharmaceutical Chemistry, Pharmaceutics, Quality Assurance (QA), Pharmacology and Pharmacognosy, and were further segregated based on their experience. The responses of each of this group were analysed separately.

Firstly, views of professionals having Chemistry as their M Pharm specialisation were analysed and are presented in Table 6 and 7. Professionals from the Industry having less than 2 years of experience or who are fresher's and recently joined industry stated that there exists a gap as compared to faculty having the same experience. This is because; the candidates who have recently joined in industry feel that this is an all-together different world for them. They have never worked in such an environment earlier and are not acquainted with the type of work being conducted in industry. This is not the case, in respect of candidates working in academic institutions. $100 \%$ faculty respondents with 2 to 5 years of experience were of the opinion that there exists a gap in between industry and academia. Whereas, majority of the Professionals from industry having more than 5years of experience had opined that there exists a gap, as compared to faculty having same experience. Overall, respondents with an experience of 5-10 years were the ones who strongly felt the gap and reasoned for the need of additional courses. Respondents from this category 
also stated that deep knowledge Synthetic aspects of organic chemistry which is required in API industry is not taught in pharmacy curriculum, which is covered in Bachelor of Science (BSc) and Master of Science (MSc) courses in Chemistry. This results in a competition between M. Pharm students and science graduates and post graduates. They also stated that the salary expectations of Science post-graduates are lower as compared to post-graduate students of Pharmaceutical sciences and hence many a times pharmacists lose out on their opportunity because of this competition.

In order to bridge the gap, it is required that the students have an exposure to latest developments in the industry and should have knowledge of domains like Drug designing, Characterization of drug molecules and Computer aided drug designing. Additional courses like short term courses or diploma courses for training students in handling sophisticated instruments like HPLC, HPTLC, Ultrashort column chromatography, GC, IR, NMR, Mass spectroscopy. Some industry professionals were of the view that apart from research \& development and production, Supply chain Management is an upcoming area in the industry, which can be looked upon as a potential career option. Some respondents were of the opinion that students should be thorough in areas like cGMP guidelines, calibration of equipment, method development \& validation, statistical analysis, bio-analysis and documentation.

Secondly, analysis of the responses of professionals with Pharmaceutics specialisation or those working in the area of formulation \& development or product development reveals that those with an experience of 2-5 years in academics and 5-10 years in the industry strongly feel that there is a gap in industry and academia. A significant variation is observed in the responses received from both these population groups.

Surprisingly faculty who have recently joined the profession having less than 2 years of experience were of the view that additional courses are required to be taught to the students to make them employable, as compared to their counterparts in Industry. There is no significant variation observed in the opinion of faculty and industry having 2-5, 5 - 10 and more than 10 years of experience. Many respondents stated that there is absolutely no need of too many specialisations at the post-graduate level. Instead, the pharmacy curriculum should consist of only four specialisations viz. Pharmaceutics, Pharmaceutical Chemistry, Pharmacology and Pharmacognosy, and focus on imparting in-depth knowledge in those respective areas.

Industry professionals stressed the need for fully functional pilot plants in academic institutions, which helps the students to get an insight into the entire process of manufacturing of pharmaceuticals. They were also of the opinion that industrial training should be mandatory in pharmacy curriculum. Institutions should take an account of every student about serious completion of industrial training. Similarly, industry should be willing to take students at undergraduate and post graduate level as trainees in their organisation. This will definitely reduce the gap, and future pharmacists will be aware of current trends, work culture and handling \& working of different types of machinery in the industry. This will help build confidence in budding pharmacists which will definitely help them to get better opportunities.

Many professionals also suggested that students should have thorough knowledge of Pharmacokinetic and Pharmacodynamic concepts. Short term courses like Pharmacoinformatics, reverse engineering. Diploma in packaging technology, polymer chemistry is also useful to students. Students should be aware of current aspects of formulation and manufacturing technique, product development, delivery and compliance, concepts of pharmaceutical engineering and pre-formulation. They should have an exposure to practical aspects like technology transfer, market research and batch manufacturing for better employment opportunities.

Further, views of faculty and industry professionals having QA as their specialisation or working in the same area in industry were analysed. From the table 10 it is clear that industry professionals with an experience of less than two years and those with more than 10 years of experience perceive the gap strongly as compared to academicians with same level of experience, and there exists a significant variation in their views. Whereas, a significant percentage of respondents with an experience of 5-10 years are of the opinion from industry and academics advocated for the requirement of additional courses to be taken by students. Respondents from this category suggested that students should be aware of ICH guidelines, cGMP regulations, USFDA guidelines, Regulatory affairs, Dossier preparation, patent filing procedures, documentation, validation, preparation of SOPs, concepts of Biostatistics. Students can do Diploma courses in Pharmacovigilance, data management which will enhance their skills leading to better prospects.

Opinions of faculty and people working in industry having Pharmacology specialisation are shown in Table 12. It is observed that Industry professionals irrespective of their experience agree that there exists a gap as compared to faculty with a similar level of experience. The difference in the opinion of faculty and industry is substantially visible in the group of respondents with 5 - 10 years and more than 10 years of experience. 
From Table 13 it is observed that majority of the industry professionals think that there is need of additional courses and is predominantly seen from the responses of industry professionals with an experience of $5-10$ years. Since India is a manufacturing hub for generic drugs, professionals with pharmacology specialisation have lesser opportunities as they are more suitable for organisations involved in drug discovery and research. ${ }^{17}$ Unfortunately very few companies are actually involved in this process in India and certain Innovator companies based in India have their R \& D units outside India, thus limiting the scope of Pharmacologists. Moreover, allopathic and ayurvedic doctors (Physicians) with a master's degree in Pharmacology also pose a tough competition to pharmacy post-graduates with pharmacology specialisation. Many a times they are required to work as assistants under doctors in various organisations because doctors are responsible for the conduct of clinical trials.

Most of the professionals in this group stressed on the need of through knowledge of cell biology as it is the most important aspect for the conduct of clinical trials. Unfortunately, cell biology is not a part of the pharmacology specialisation at the post-graduate level in pharmacy in most of the Universities.

For better prospects, students can enrol in Diploma programs in clinical research \& clinical trials. Short term course on Pharmacovigilance and scientific writing can also help students in their employment. Clinical toxicology, clinical validations were also suggested as potential areas which could increase the employability factor of students.

Opinions of faculty and professionals from industry having Pharmacognosy specialisation or working in the area of natural products were recorded and analysed as presented in Table 14 and 15. It was observed that percentage of industry professionals with an experience of less than two years who perceive a gap between industry and academia are more than their academic counterparts, whereas opposite results were seen in case of respondents with an experience of $5-10$ years. Respondents from both these groups also suggested various additional courses for students and reasoned for them. No significant difference of opinion was observed in respondents having 2 - 5 years and more than 10 years of experience. Faculty members with more than five years of experience also stated that students with Pharmacognosy specialisation find it difficult to secure jobs and mostly land up taking jobs not related to their specialisation.

In India, there are a limited number of industries which work on natural products as compared to industries working and producing synthetic drugs, and hence the requirement of post-graduates in Pharmacognosy is very limited. Moreover, industries in the Natural products domain prefer Ayurvedic doctors as compared to pharmacists for formulation and development of herbal medicines. Research and development in the herbal industry is also negligible due to the insufficient regulatory guidelines and limited market in developed countries, thus reducing the scope of Pharmacognosy post-graduates in this area. ${ }^{18}$

The respondents from industry and academia were mostly of the view that in order for Pharmacognosy post-graduates to get absorbed by the industry, they need to have a good exposure to phytochemical investigations and formulation \& development approaches of herbal preparations. Knowledge of Sanskrit language would be an added advantage as most of the literature on natural medicines is available in Sanskrit. ${ }^{19,20}$ It is pertinent to note that Sanskrit is an integral part of the curriculum of Bachelors course in Ayurvedic medicine and surgery.

\section{CONCLUSION}

This research corroborates that there exists a significant gap in the skill-sets required by the pharmaceutical industry and what the students acquire while pursuing post-graduate courses. From the study, it appears that instead of expanding the horizon of specialisations in post-graduate courses in pharmaceutical sciences, students should be imparted in-depth knowledge of the core subjects and fundamental concepts and should be exposed to the latest technological know-hows used in the industry. Students should be encouraged to take-up relevant research projects during their post graduate study, so as to make them understand the intricacies of real life problems being faced by the industry. In order to achieve the overall development of students, teachers are also required to update their knowledge and sincere efforts should be taken by academic regulators in this direction. For continuous up-gradation of faculty and students, collaboration between industry and academia for conducting guest lectures, seminars, collaborative industrial projects, industrial training \& consultancy is essential. Thus establishing a strong industry-academia interface. The curriculum needs be updated at regular intervals with the active participation of industry peers. These measures, if implemented and practised, will definitely help bridging the perceived gap between Industry and academia, and will help produce competent and able pharmacists, who would take India to the next level in the field of pharmaceutical sciences. 


\section{ACKNOWLEDGEMENT}

Authors express deep gratitude to academicians from various academic institutions and professionals working in pharmaceutical industries for their support and providing their valuable time for filling questionnaires as well as for discussion during the visit for the current study.

\section{CONFLICT OF INTEREST}

None of the authors have any personal or financial conflicts of interest.

\section{ABBREVIATION USED}

NIPER's: National Institute of Pharmaceutical Education and Research; PG: Post Graduate; M. Pharm: Masters in Pharmacy; HPLC: High Performance Liquid Chromatography; HPTLC: High Performance Thin Layer Chromatography; GC: Gas Chromatography; IR: Infra Red; NMR: Nuclear Magnetic Resonance; cGMP: Current Good Manufacturing Practices; QA: Quality Assurance; ICH: International Conference on Hormonisation; USFDA: United States Food and Drug Administration; SOP's: Standard Operating Procedures; R\&D: Research and Development.

\section{REFERENCES}

1. Praneta D. An Overview about Pharmacy Education in India. Indian Journal of Research in Pharmacy and Biotechnology. 2013;1(3):329-32

2. Ministry of Pharmaceuticals, Government of India, Annual Report 2016-2017, [Internet]; [cited 2017 April 10]; Available from tp://pharmaceuticals.gov.in/sites/ default/ files/Chemical\%20Pharma $\% 20-2016-17 \% 20$ English $\% 20$ Final $\% 20 \% 20$ for $\% 20$ mail\% 20\%282\%29.pdf
3. Daniel LB, A looming Joblessness Crisis for new pharmacy Graduates and implications it holds for the Academy, Am J Pharm Educ, 2013;77(5)90:1-5

4. Breimer DD. Future training needs in the pharmaceutical sciences: academiaindustry. Eur J Pharm Sci. 2001;12(4):347-52.

5. Kimberly BZ, David FK, and Donald LS, Evaluating the Pharmaceutical Industry's Need for Graduates with a Bachelor of Science Degree in Pharmaceutical Sciences. Am J Pharm Educ, 2003;67(1):14

6. Basak SC, and Sathyanarayana D, Pharmacy Education in India, Am J Pharm Educ, 2010;74(4):68

7. Tharappel LJP, Kaur G and Buttar HS , Pharmaceutical Education in India: Past, Present and Future., J. Pharm. Sci. \& Res. Vol. 2014;6(8):278-81

8. Aicte-india.org [Internet]. New Delhi : All India Council for Technical Education.; [cited 2017 April 10]; Available from : http://www.aicte-india.org/ dashboard/pages/dashboardaicte.php

9. Mangasuli S, Rajan S, and Khan SA, A Decade of Pharmacy Practice Education in India, Am J Pharm Educ, 2008;2(1):16.

10. Basak SC, van Mil JF, Sathyanarayana D. The changing roles of pharmacists in community pharmacies: perception of reality in India. Pharmacy world \& science. 2009;31(6):612-8.

11. Kotamballi N, Murthy C, Pharmacy Education system in India: Time to revisit teaching And training modules to meet global expectation, Indian Journal of Pharmaceutical Education and Research, 2014;48(2):1-3.

12. Mooney KG. Challenges faced by the pharmaceutical industry: training graduates for employment in pharmaceutical R\&D. European journal of pharmaceutical sciences. 2001;12(4):353-9.

13. Berry TM, Chichester CO, Professional Technical Standards in Colleges and Schools Of Pharmacy, Am J Pharm Educ, 2011;75(3):1-7

14. Lilian H, Jeffrey C, Development of Competancy Based Assessment Process for Advanced Pharmacy Practice Experiences, Am J Pharm Educ, 2006;70(1):1-11

15. Dandiya PC. Pharmaceutical education in India: An introspection for better future. Pharma Times. 2011;43(3):19.

16. Babar ZUD, Scahill SL, Akhlaq M, Garg S, A bibliometric review of pharmacy education literature in the context of low- to middle-income countries, Currents in Pharmacy Teaching and Learning, (2013):1-15

17. Mathew P. Generic drugs: Review and experiences from South India. Journal of Family Medicine and Primary Care. 2015;4(3):319-23.

18. Sahoo N, Manchikanti P. Herbal Drug Regulation and Commercialization: An Indian Industry Perspective. Journal of Alternative and Complementary Medicine. 2013;19(12):957-63.

19. Subotyalov MA, Druzhinin VY. Moscow: Filosofskaya Kniga; 2015. Ayurveda: Sources and Characteristics: Monograph; p. 170

20. Patwardhan B. Bridging Ayurveda with evidence-based scientific approaches in Medicine. The EPMA Journal. 2014;5(1):19

\section{SUMMARY}

- The Indian Pharmaceutical industry is growing at a rapid pace and needs competent and trained pharmacists to supplement its growth.

- In order to meet the requirements of the pharmaceutical industry, there had been a substantial increase in the number of academic institutions offering graduate and post graduate courses in pharmaceutical sciences since the last decade.

- In spite of the increase in the number of institutions offering post-graduates courses, availability of readily employable manpower remains a concern for the pharmaceutical industry.

- Primary research was done to identify the gap in between industry and academia to collect the views of academicians and industry professionals. Data was analyzed and interpreted using statistical methods.

- The overall outcome of the research establishes that educational reforms in terms of making a robust curriculum with active participation of the industry is the need of the day. 


\section{PICTORIAL ABSTRACT}

Due to the rapid development and changing technology, academic institutions have not been able to produce pharmacists who are productive and readily employable. Thus, resulting in a gap between industry and academia. The present study aims to identify the gap which exists in industry and academia by taking views of select professionals from the pharmaceutical industry and faculty from academic institutions.

320 faculty from 38 academic institutions and 312 professionals from 30 industries were selected for the study.

Results were quantified on the basis of their M. Pharm specialisations or their area of work in the industry. The study results reveal that revamping of post graduate education in pharmaceutical sciences by focusing on industry-academia collaboration, building fundamental concepts, emphasizing practical exposure to latest technologies and techniques used in industry, encouraging faculty and students for industrial training can help bridge the gap in industry and academia.

\section{About Authors}

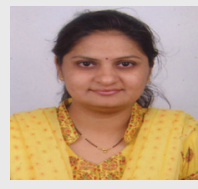

Gouri Palsokar: Is an Assistant Professor at NCRD's Sterling Institute of Pharmacy, Nerul, Navi Mumbai, Maharashtra, India. She is an M.Pharm from RTM Nagpur University. Her career spans over a decade with over 11 years in academics and one year in the Industry. Her areas of interest includes formulation \& development of herbal preperations. She has extensively researched on various issues in Pharmaceutical Education.

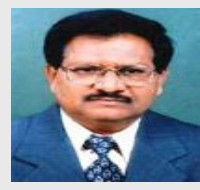

Prof M.R. Tajne: Is an Ex-professor at Department of Pharmaceutical Sciences, RTM Nagpur University. His area of interest is Drug analysis. He has a rich experience in the area of teaching various courses in Pharmaceutical Sciences and has been a consultant to various Pharma Industries. He has also executed various research and consultancy assignments.

Cite this article: Palsokar G, Tajne M. A Study on the Perceived Gap in Between Industry and Academia with Reference to the Curriculum of Post-Graduate Courses In Pharmaceutical Sciences in india. Indian J of Pharmaceutical Education and Research. 2018;51(1):10-20. 